\title{
Development of Creativity Instrument through Rasch Model Analysis
}

\author{
Dindin Abdul Muiz Lidinillah ${ }^{1}$, Mila Aprilia ${ }^{1, *}$, Dodi Suryana $^{2}$, Aslina Binti Ahmad ${ }^{3}$ \\ ${ }^{1}$ Department of Elementary Teacher Education, Universitas Pendidikan Indonesia, Indonesia \\ ${ }^{2}$ Department of Guidance and Counseling, Universitas Pendidikan Indonesia, Indonesia \\ ${ }^{3}$ Department of Psychology and Counseling, Universiti Pendidikan Sultan Idris, Malaysia
}

Received January 11, 2020; Revised February 25, 2020; Accepted March 12, 2020

Copyright $\bigcirc 2020$ by authors, all rights reserved. Authors agree that this article remains permanently open access under the terms of the Creative Commons Attribution License 4.0 International License

\begin{abstract}
This research was motivated by the diversity of the creative abilities of students. The research objective was to show the description of the development of instruments owned creativity skills of elementary school students. This study uses Rasch models analysis to be more precise and generates relevant data in the completion of the process of analysis instruments. Participants are 5-grade students from four schools in Tasikmalaya, a total of 100 respondents. Data collection tool was in the form of the skill of creating an instrument to measure the success rate between the instruments of creativity to be developed to the level of students' creativity. The results showed that the development of creative instruments is mostly located in a very good category with a proportion of $60.8 \%$. Through this analysis, it is noted that the level of difficulty of the instrument is greater than the level of students' creativity ability, evidenced by the results of research that shows the number of items on the separation and reliability is greater than the number of a person on separation and reliability. Besides, developing creativity instruments can be accepted by all respondents (not experienced gender bias), and can be easily done by one of four schools in Tasikmalaya (biased place).
\end{abstract}

Keywords Creativity Skills, Rasch Model Analysis

\section{Introduction}

In this millennial era, humans are emphasized to do many things. In addition to using reason as the cognitive aspects to be able to do a lot of work, people also need skills as the basic driving force in the implementation of the work. One of them uses creativity skills. Creativity is essential for human life. In the world of education today, especially at the primary school level, teachers are trying to instill in students the skills aspect by encouraging students to creativity in its class. Not only through artistic subjects, but the creativity of the students could be raised through all subjects as well as on various aspects of life starting from the school environment. Schools as social institutions should be able to provide a climate filled with nuances of peaceful life, mutual respect, affection, fairness, and mutual respect so that students' creativity will continue to be trained through the process of problem-solving if there is a gap in their social scope at school [1]. Creativity is not only on the scope of art, but creativity is also within the scope of the economy and in everyday life such as housework or other activities that require more extensive knowledge and experience. By using the skills of creativity, people can do things like creating a very intense work, socialize well in a community, use technology very well, and can solve many problems in their daily lives. That's why Guilford said that creative people are those who always have new ideas so-called unusual people [2]. Creativity can be generated through a process that is very occupied. Creativity should always be grown through problem-solving activities[3]-[5]. Students are creatively tend to have a good personality like learning to be more independent, responsible, work hard, have high motivation, optimism, have a great curiosity, self-confidence, being open, tolerant, and rich in ideas. The good nature, of course, is realized through a strong boost of student motivation. Motivation can play a catalytic role in the students' creativity. Thus, the skill level of students' creativity can grow if it is accompanied by high student motivation at the time to follow the teaching and learning activities in the classroom[6], [7]. That's why it is very important to apply creativity skills to the students through the learning process starting from the primary school level, for ease in overcoming various problems which would occur in the wider environment. 
To education, creativity is seen as a benchmark of students to be able to create works by him that had been met. The student can vote in his life so that he could use his creativity in the education process. Intellectual and sensibility, rational and irrational, as well as the mind and emotional sensitivity, will be balanced when applied to the activities of creativity by students in the school, through the guidance of teachers to students which is more emphasis on the psychomotor and attitude formation. That's why teachers must be able to be a good model for students [8]. Also, the school is responsible for several tasks concerning the development of student creativity, among others: (a) through creativity skills, students can develop concepts that are necessary for their daily lives, (b) students can take decisions about conscience, to develop morality and other things related to values, (c)students can achieve personal freedom, and (d) students can develop an attitude toward groups and social institutions. In other words, creativity is very important in education which was developed by teachers to make students as qualified human[9]-[13].

This study is the result of an analysis of the application of Rasch models. Rasch model is used because it can provide a solution to the shortcomings of previous models [14]. Rasch model is a result of the development of a model of the CTT (classical test theory) and IRT (item response theory). Many critics in CTT models, such as the reliability coefficient that depends on the number of samples, measurement scale are not linear, limitations on the range of scores, and the balance of negative-positive correlation. CTT later developed into one of the IRT logistical parameter variations which is 1PL, which eventually developed into Rasch models. So far, Rasch models can measure the data better and accurately, and meet the 5 principles of measurement model, namely: (1) capable of delivering linear data with the same interval, (2) can predict the missing data, (3) may estimate the data appropriately, (4) capable of detecting improper models, and (5) produce data that is replicable [15]. Research that does not use the Rasch model is more likely to get a lot of shortcomings in the data obtained, such as deficiencies in the model of the
CTT earlier.

\section{Research Methodology}

Research is seen as a scientific activity that is very important for humans. This study uses an analytical thought process, meaning that researchers always connect one object with another object which is necessary for the object first. The approach used in this study is a quantitative approach using descriptive methods as research focusing on actual problems through the process of collection, collation or classification, processing, and interpretation of data [16]-[18]. The study population was 5 -grade students from four schools in Tasikmalaya. Sampling was conducted using a cluster sampling method, namely sampling based on a group [19]. Following the study sample, it can be seen in Table 1 .

Table1. Research Sample

\begin{tabular}{|c|c|c|c|}
\hline \multirow{2}{*}{ School } & \multicolumn{2}{|c|}{ Demographics } & \multirow{2}{*}{ Amount } \\
\cline { 2 - 3 } & Male & Female & \\
\hline Elementary School 1 & 13 & 14 & 27 \\
\hline Elementary School 2 & 17 & 12 & 29 \\
\hline Elementary School 3 & 12 & 9 & 21 \\
\hline Elementary School 4 & 10 & 13 & 23 \\
\hline Amount & 53 & 47 & 100 \\
\hline
\end{tabular}

\section{Results}

\subsection{Development of the Student Creativity Unidimensionality Based Analysis Instrument}

Based on table Dimensionality, Raw variance explained by measures and Unexplained variance in 1st to 5th contrast is an element to consider in the analysis instrument of this creativity. Note Table 2 below.

Table 2. Development of Student Creativity Instrument Based on Unidimensionalitas

\begin{tabular}{|c|c|c|c|c|}
\hline & & Eigenvalue & Observed & Expected \\
\hline Total raw variance in observations & $=$ & 152.978 & $100.0 \%$ & $100.0 \%$ \\
\hline Raw variance explained by measures & $=$ & 92.978 & $60.8 \%$ & $60.5 \%$ \\
\hline Unexplained variance in 2nd contrast & $=$ & .9635 & $6.3 \%$ & $16.1 \%$ \\
\hline Unexplained variance in 3rd contrast & $=$ & .5807 & $3.8 \%$ & $9.7 \%$ \\
\hline Unexplained variance in 4th contrast & $=$ & .0189 & $.1 \%$ & $.3 \%$ \\
\hline Unexplained variance in 5th contrast & $=$ & .0004 & $.0 \%$ & $.0 \%$ \\
\hline
\end{tabular}


While unexplained variance in 1 st to 5 st contrast of residuals, are respectively $29.0 \%, 6.3 \%, 3.8 \%, 0.1 \%$ and $0.0 \%$. By looking at the data, it can be seen that there is a category that is greater than the value of $15 \%$, which means that the construct of the creativity instrument does not measure one variable that is aligned.

\subsection{Development of the Student Creativity Based Analysis Wright Map (Person-Item Map)}

Based on the results of data analysis using Rasch analysis models, wright map analysis information was in Table 3 below.

Table 3. Development of Student Creativity Instrument Based on Analysis Wright Map

MEASURE

3

2

0

$-1$

$-2$

$-3$

$<$ more $>\mid<$ rare $>$

$020708283259 \mathrm{SIT}$ S

293060616263798081 |

12316465666768697071727882858689

10506113334353637384041424374909197 +

4546495075838488

$09103951535456739293949596 \mathrm{M}$

13144447485587 | S6

$+\mathrm{M} \mathrm{S} 4$

109899

2052

| S1 S2

$\mathrm{S} \mid \mathrm{S}$

161719

15

18 |

$\mid \mathrm{T}$

$2122+$

2324

2576

26

$2777+$

$$
<\text { less }>\mid<\text { freq }>
$$


Position creativity above instruments spread between logit -4 to 3 , with the level of difficulty of the whole item is located between logit -1 to 2 . Then the position of the student's ability spread between -2SD to $+1 \mathrm{SD}$ and most are in between logit $-1 \mathrm{SD}$ to $+1 \mathrm{SD}$, On average ability students' creativity which is worth +0.56 was above average logit items, which amounted to 0.00 . Based on the level of difficulty of the instrument, all items are about to be among -1SD and + 1SD and no number is above the + 2SD. It can be concluded that the level of creativity of students is not greater than about the item level in the instrument of creativity, but some students' creativity abilities are more likely to balance with the level of creativity instrument. So that all items are in a matter of creativity instrument to encourage students to think creatively.

\subsection{Development of the Student Creativity Based Item Analysis Instrument}

\subsubsection{Item Difficulty Levels Analysis}

Table 4. Development of Student Creativity Instrument Based on Item Difficulty Levels Analysis

\begin{tabular}{|l|c|c|c|c|c|c|}
\hline Entry Number & 5 & 6 & 4 & 1 & 2 & 3 \\
\hline Measure & 0,1 & 0,15 & 0,06 & $-0,7$ & $-0,7$ & $-0,68$ \\
\hline Item & S5 & S6 & S4 & S1 & S2 & S3 \\
\hline Mean & \multicolumn{7}{|c|}{0,00} \\
\hline SD & \multicolumn{7}{|c|}{00} \\
\hline
\end{tabular}

From the table, it is known the value of SD (standard deviation) is 0.90 . If the value of SD is combined with the average value of the logit, then the following criteria is obtained: a) extremely difficult if value $>0.90$, b) difficult if values between 0.00 to $0.90, c)$ easy if the value of between -0.90 to $<0.00$, and d) very easy if the value of $<-0.90$. According to the table, it is informed that: (1) there is one item that belongs to the category very difficult, which is item number 5, (2) there are two items that are categorized as difficult, that is number 6 and 4, (3) there are 3 items included easy categories, ie the number 1,2, and 3 , and (4) there are no question items included in the category very easily.

\subsubsection{Item Conformance Levels Analysis}

Table 5. Development of Student Creativity Instrument Based on Item Conformance Levels Analysis

\begin{tabular}{|c|c|c|c|c|c|c|c|}
\hline \multicolumn{2}{|c|}{ Entry Number } & 4 & 6 & 5 & 1 & 2 & 3 \\
\hline \multicolumn{2}{|c|}{ Measure } & .06 & .15 & 1.84 & -.68 & -.68 & -.68 \\
\hline \multirow{2}{*}{ Outfit } & MNSQ & 1.63 & 1.39 & 1.15 & .68 & .68 & .68 \\
\cline { 2 - 8 } & ZSTD & 3.85 & 2.53 & .84 & -2.62 & -2.62 & -2.62 \\
\hline \multicolumn{2}{|c|}{ PT Measure Corr } & .42 & .38 & .52 & .90 & .90 & .90 \\
\hline \multicolumn{2}{|c|}{ Item } & S4 & S6 & S5 & S1 & S2 & S3 \\
\hline
\end{tabular}

Criteria conformity item (item fit) and the mismatch items (outlier or misfit) seen from the level of conformity of the items are a) the value OUTFIT MNSQ $>0.5$ and $<$ 1.5 , closer to the value of 1 , then the item about the better, $b$ ) OUTFIT value ZSTD $>-2.0$ and $<+2.0$, getting closer to a value of 0 , then the item about getting better, and c) PT MEASURE CORR nice if the item is worth being between $>$ 0.4 and $<0.85$. An item can be deemed fit matter if it meets at least 1 of the 3 criteria. According to the table, there was information that: (1) there is one item that is a misfit in MNSQ OUTFIT value, which amounted to 1.63 at about item number 4 , (2) there are four items that misfit on OUTFIT ZSTD value, the item about the number 1, 2, 3, and 4 , and (3) there are 4 items that misfit on the value of PT MEASURE CORR, the item about the number 1, 2, 3, and 6.

\subsubsection{Rating Scale}

Table 6. Development of Student Creativity Instrument Based on Rating Scale

\begin{tabular}{|c|c|c|c|c|c|}
\hline Category Label \& Score & 0 & 1 & 2 & 3 & 4 \\
\hline Observed Average & -2.30 & -.91 & .46 & 01.18 & 02.05 \\
\hline Andrich Threshold & NONE & -1.95 & -.93 & .83 & 02.05 \\
\hline Category Measure & $(-3.26)$ & -1.53 & -.03 & 01.52 & $(3.32)$ \\
\hline
\end{tabular}

Results of the analysis observed average and Andrich Threshold the rating scale shows the change value is increasing. Thus it can be stated that the difference in the answer to the instrument of creativity can be understood by students as respondents.

\subsubsection{Item Detection Bias}

Research creativity instrument uses detection of gender bias and bias point to find out the problems that can be easily done by some respondents and to determine the portion of respondents who will be harmed in the completion of an item about the instrument such creativity. Figure 1 below is a graph of the detection of gender bias in the instrument of creativity.

\section{Person DIF plot (DIF=\$\$4W1)}

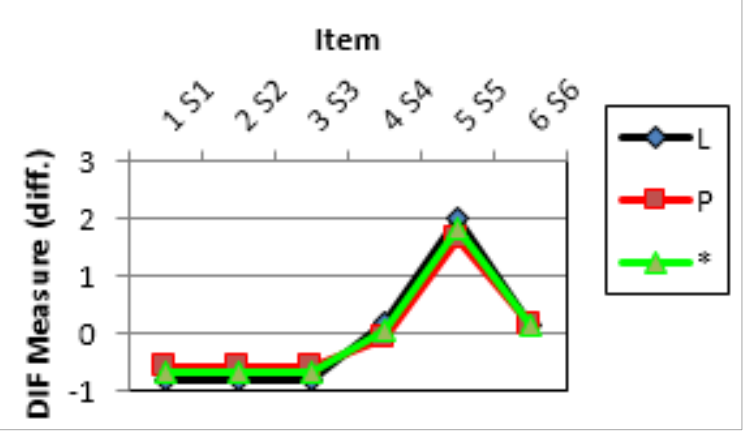

Figure 1. Gender Bias 
The graph above shows that all the items are occupied by the four schools at the same point. This means that all items can be done by all respondents and no one can work on the problems more easily than others (about not experienced gender bias). While the shape of the curve indicates the level of matter from the easiest to the most difficult questions. Item Question 5 indicates the highest curve, meaning that the question is about the most difficult of the six questions. Figure 2 below is a graph of the detection of place bias in the instrument of creativity.

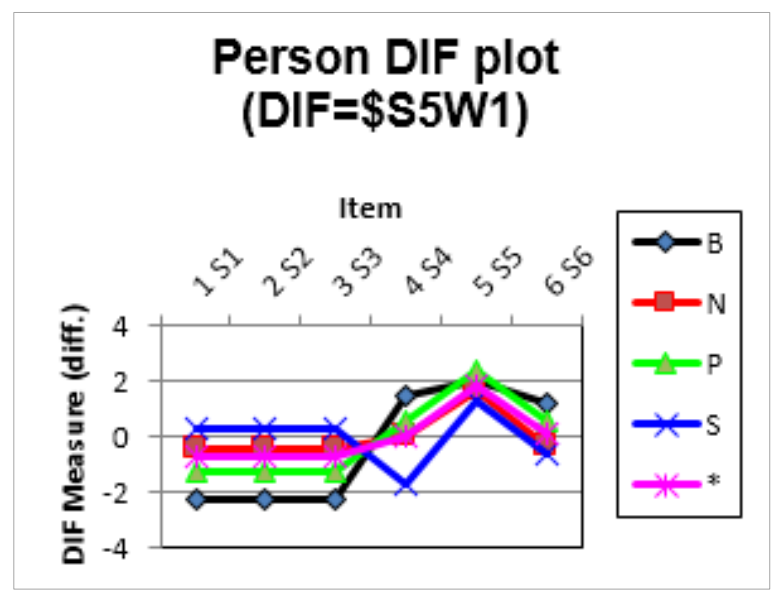

Figure 2. Place Bias

From the above graph, it appears that all of the items in question can be easily done by one school, which means that 3 of 4 schools feel aggrieved by the items contained in the instrument about the creativity. However, if viewed from any item problem, it can be identified that the item about the number 5 is not a biased place. In other words, the problem can easily be done by all respondents.

\subsection{Development of the Student Creativity Abilities Based Analysis}

\subsubsection{Analysis of Individual Abilities}

In the Person table Measure, known instruments have an SD value of 1.33 and an average value logit worth 0.56 . If the value of SD is combined with the average valueoflogit (mean), then the following criteria is obtained: a) high abilities if value $>0.56$ sum of SD and mean), b) abilities being if values between $0.77-1.89$, and c) lower abilities if the value of $<0.77$ (SD reduction results and mean). Based on data analysis person measure it, in getting the information that levels abilities of 100 respondents as follows: (1) 11 students are included in the category of abilities high, (2) 42 students are included in the category of abilities medium, and (3) there 47 students were included in the category of low ability.

\subsubsection{Analysis of Individual Compliance}

The criteria for measuring the level of individual suitability is as follows: a) if OUTFIT MNSQ value closer to the value of 1 , the instrument with the level of individual suitability, the better; b) if OUTFIT ZSTD value closer to the value 0 , then the instrument to the level of individual suitability, the better; and c) if the value of PT MEASURE CORR $>0.4$ and $<0.85$ then the instrument with the better level of individual suitability. A respondent can be considered fit if it meets at least one of three criteria. Then it can be obtained that: (1) as many as 86 students declared fit and (2) as many as 14 other students give answers according to the level abilities less.

\subsection{Development of the Student Creativity Based Analysis Instruments}

The explanation can be seen in Table 7 below.

Table 7. Development of Student Creativity Instrument Based on Analysis Instruments

\begin{tabular}{|c|c|c|c|}
\hline & & PERSON & ITEM \\
\hline \multirow{2}{*}{ Mean MNSQ } & INFIT & 1,03 & 0,98 \\
\cline { 2 - 4 } & OUTFIT & 1,04 & 1,04 \\
\hline \multirow{2}{*}{ Mean ZSTD } & INFIT & $-0,27$ & $-0,41$ \\
\cline { 2 - 4 } & OUTFIT & $-0,31$ & $-0,11$ \\
\hline \multicolumn{2}{|c|}{ Separation } & 1,8 & 6,29 \\
\hline \multicolumn{2}{|c|}{ Reliability } & 0,76 & 0,98 \\
\hline \multicolumn{2}{|c|}{ Cronbach Alpha } & \multicolumn{2}{|c|}{} \\
\hline
\end{tabular}

Based on the analysis of these data tables, it can be informed that the Cronbach Alpha has a value of 0.80 which is included in the category of nice, Person Reliability worth 0.76 categorized as good, and the Item Reliability has a value of 0.98 belonging to a special category. Then the average Person INFIT MNSQ and OUTFIT MNSQ and each has a value of 1.03 and 1.04 , and the average value of Items INFIT MNSQ and OUTFIT MNSQ respectively 0.98 and 1.04. Criteria: "getting close to 1 , the better the instrument (ideal value is 1)." Meanwhile, the average Person INFIT ZSTD and OUTFIT ZSTD each has a value of -0.27 and -0.31 , and the average value INFIT ZSTD and OUTFIT ZSTD respectively -0.41 and -0.11 . While separation to Person valuable items worth 1.80 and 6.29. By using the calculation formula $\mathrm{H}=\{(4 \mathrm{x}$ separation $)+1\}$ / 3 , the data showed that the value of Separation Person is 7.53 rounded to 8 , and the value of Separation Item is 25.49 rounded to 25 .

\section{Discussion}

\subsection{Development of the Student Creativity Unidimensionality Based Analysis}

Unidimensionalitas assumed as counter reliability of a model study showed that a model has a good level of concordance dimension [20]. The findings of the research 
have shown that students' creativity skills with creativity instruments are in the very good category, that is a matter of such instruments is adequate and can bring creative thinking skills in students as respondents. Although there is one problem less relevant, meaning items that question does not measure the variables that should be in such instruments which are subject creativity of the students, but according to analysis results through Rasch models, the instrument is very good and can be received by all students as respondents.

\subsection{Development of the Student Creativity Based Analysis Map Wright (Person-Item Map)}

The average level of creativity of students is parallel to and below the average level of difficulty of the standard items. That is, all the items in a matter of creativity instrument is slightly above the ability of students' creativity. In other words, the item about the instrument still can make the students think deeply and bring out creative ideas in him so that the instrument can encourage students to further develop their creativity level. However, differences in the level of difficulty of items about this instrument do away with the level of creativity of students, so that all items in a matter of creativity instrument are acceptable and easily approved by the respondents, namely students.

\subsection{Development of the Student Creativity Based Item Analysis}

\subsubsection{Item Difficulty Levels Analysis}

Based on the analysis of grain on the development of students' creativity instrument, it is obtained that the difficulty level of questions in the instrument items has 1 item belonging to the category of very difficult, 2 relatively difficult matters, and 3 problems belonging to the category of easy matter.

\subsubsection{Item Conformance Levels Analysis}

Meanwhile, if viewed from the level of suitability item, the instruments have one question that experienced misfit judgment OUTFITMNSQ, 4 items about the experience misfit judgment OUTFITZSTD, and there are 4 questions that misfit PT MEASURE CORR judgment. So in general, all the items on this creativity instrument experienced a misfit or an outlier. The outlier is defined as an observation data that is inconsistent in series [21]. 4 of 6 items matter are declared in a misfit and as many as 2 grains of items in the instrument of creativity declared fit in the sense of normal function and can be understood correctly by students.

\subsubsection{Rating Scale}

Based on the rating scale analysis, it is obtained that the differences in response to the instrument of creativity can be understood by students as respondents. The rating scale is defined as an assessment that is based on a certain scale in order from lowest to highest. Rating scale is in view as the raw data in the form of numbers and interpreted in a descriptive sense [22], [23].

\subsubsection{Item Detection Bias}

The results of the analysis by gender bias in mind there are no items were biased. That is, all items can be received by male and female. This gender bias occurs where one party is harmed so that it is injustice[24]. Gender bias is a process that has been difficult in the research process. There is a weakness in activity measure gender bias to produce a consistent value. "Most studies have found no gender differences in creativity, and review those that have found differences have not found any consistent pattern of difference". So it is difficult to show how gender differences in the instruments that may explain differences in the level of creativity of students. However, this study uses a Rasch analysis model that can measure the level of a better gender bias [25], [26]. While the results of the analysis of bias are based on the place, it is known that the majority of respondents were more likely to be harmed in the works about the item, it means this creativity instrument was the biased place. Only one of the four schools that are prone to do each item on the matter. This is because the culture is different in each region and can cause differences in the level of creativity of students. There is a comfortable and peaceful place to be more constructive on the ability of students' creativity skills [27]. But even so, the losses suffered by most of the respondents are not too flashy, because the difference between the level of difficulty of all items on the instrument with the level of creativity of the respondents is not too large. Thus, all the items on the instrument can still be accepted easily by the students.

\subsection{Development of the Student Creativity Abilities Based Analysis}

Ability is seen as an individual's ability to perform various tasks in a job [28]. In connection with the results of the analysis of individual abilities of 100 respondents, information provided that 11 students were included in the category of high ability, 42 students were included in the category of abilities moderate, and 47 students were included in the category of low ability. While based on the analysis of the level of the individual suitability, it is known that as many as 86 students declared fit in the sense of providing answers according to the level abilities, and 14 other students give answers according to the level abilities less.

\subsection{Development of the Student Creativity Based Analysis Instruments}

Analysis of these instruments serves to determine the extent of the student's ability to understand the material. 
Based on the results of the analysis instrument, information obtained that the interaction between students and the overall question items was included in the category of nice. Then the Person Reliability showed a nice category as well, and the Item Reliability showed a special category. In other words, the average person or items approach the ideal criteria, meaning that person and item quality is good, as well as the balance of these two elements is applied. Then concerning the value of the separation, it is known as a criterion that the greater the value of separation, the better the quality of the instrument as a whole person. Based on the analysis, it is informed that person separation value is 8 , while the separation of items worth 25 . This implies that the respondents in the study of creativity instrument have a variety of capabilities that can be categorized into 8 groups and item difficulty of items spread out in 25 groups ranging from groups the easiest to the most difficult.

\section{Conclusions}

The research instrument of creativity is measured using analysis Rasch model because 1)it can determine whether or not an item about the bias, 2) Raschmodel analysis can measure the number of items and the respondent freely, meaning that the data generated is not dependent on the number of items or the number of respondents, 3) Rasch model analysis can measure any individual difficulties of items about the instrument, and then turn it into a data in a common scale, and 4) Rasch model analysis can measure the data in a way that is easy to set and relevant[29]. Based on the results of the collection, processing, and analyzing data through the Rasch model analysis instruments concerning students 'creativity skills, they can be summed up as follows: (1) In general, the development of students' creativity skills instruments are in the very good category. This means that creativity skills of the students is a balance with the items in the instrument that is given and can trigger the development of students' creativity as a respondent, (2) In general, the strength of the items about greater than the ability of the creativity of the students so that students can develop a level of creativity to the maximum, (3) In general, items about the instrument did not experience gender bias, this means that all questions can be accepted by male and female respondents, and (4) in general, items on the instrument was biased place, meaning that the entire matter could be more easily done by one of the four schools, but the items about still can be accepted easily by all students because the difference is not too much between the difficulty level of the instrument with the skill level of students' creativity.

\section{Acknowledgements}

Thanks to the lecturer Evaluation of Learning in Elementary School who has allowed working on this article.

\section{REFERENCES}

[1] U. Suherman, N. Budiman, D. Suryana, E. S. Yudha, A. B. Ahmad, and M. N. Bin Saper, "Dimension of peace culture based on Al-quran values," Univers. J. Educ. Res., vol. 7, no. 10, pp. 2171-2178, 2019. DOI: 10.13189/ujer.2019.07 1015.

[2] M. A. Runco and G. J. Jaeger, "The Standard Definition of Creativity," Creat. Res. J., vol. 24, no. 1, pp. 92-96, 2012.DOI: $10.1080 / 10400419.2012 .650092$.

[3] T. Y. E. Siswono, "Leveling students' creative thinking in solving and posing mathematical problem," J. Math. Educ., vol. 1, no. 1, pp. 17-40, 2010. DOI: 10.22342/jme.1.1.794. $17-40$.

[4] H. Tambunan, "The Effectiveness of the Problem Solving Strategy and the Scientific Approach to Students' Mathematical Capabilities in High Order Thinking Skills," Int. Electron. J. Math. Educ., vol. 14, no. 2, pp. 293-302, 2019. DOI: $10.29333 /$ iejme/5715.

[5] S. Hemlin, C. M. Allwood, and B. R. Martin, "Creative knowledge environments," Creat. Res. J., vol. 20, no. 2, pp. 196-210, 2008.DOI: 10.1080/10400410802060018.

[6] A. M. Alzoubi, M. F. Al Qudah, I. S. Albursan, S. F. Bakhiet, and A. S. Abduljabbar, "The Effect of Creative Thinking Education in Enhancing Creative Self-Efficacy and Cognitive Motivation," J. Educ. Dev. Psychol., vol. 6, no. 1, p. 117, 2016. DOI: 10.5539/jedp.v6n1p117.

[7] C. Fischer, C. P. Malycha, and E. Schafmann, "The influence of intrinsic motivation and synergistic extrinsic motivators on creativity and innovation," Front. Psychol., vol. 10, no. FEB, pp. 1-15, 2019. DOI: 10.3389/fpsyg.201 9.00137 .

[8] C. A. Warren, Towards a pedagogy for the application of empathy in culturally diverse classrooms, vol. 46, no. 3 . 2014. DOI: 10.1007/s11256-013-0262-5.

[9] B. Gunawan, B. Setiawan, and M. Rohmadi, "Education Characteristics of Students in Debate Learning Sma Negeri 1 Karanganyar," Ling. Didakt. J. Bhs. dan Pembelajaran Bhs., vol. 11, no. 1, p. 84, 2017. DOI: 10.24036/ld.v11i1.7 704.

[10] A. Craft, "The limits to creativity in education: Dilemmas for the educator," Br. J. Educ. Stud., vol. 51, no. 2, pp. 113-127, 2003.DOI: 10.1111/1467-8527.t01-1-00229.

[11] K. ÜLGER, "the Role of Art Education on the Creative Thinking Skills of Students in Music and Visual Arts Education: a Comparison From the Perspective of the Music Education," Abant İzzet Baysal Üniversitesi Eğitim Fakültesi Derg., vol. 18, no. 2, pp. 1175-1195, 2018.DOI: 10.17240/aibuefd.2018..-396608.

[12] J. Vaughan, C. J. Mallett, K. Davids, P. Potrac, and M. A. López-Felip, "Developing Creativity to Enhance Human Potential in Sport: A Wicked Transdisciplinary Challenge," Front. Psychol., vol. 10, 2019. DOI: 10.3389/fpsyg.2019.0 2090. 
[13] D. Suryana, N. Rusmana, S. F. Ramadhanti, and N. Budiman, "The autonomy of learning in elementary school," Int. J. Sci. Technol. Res., vol. 9, no. 2, pp. 2727-2731, 2020.

[14] Nurhudaya, A. Taufik, E. S. Yudha, and D. Suryana, "The Raven's advanced progressive matrices in education assessment with a Rasch analysis," Univers. J. Educ. Res., vol. 7, no. 9, pp. 1996-2002, 2019. DOI: 10.13189/ujer.20 19.070921 .

[15] B. Sumintono, "Model Rasch untuk Penelitian Sosial Kuantitatif," Makal. kuliah umum di Jur. Stat. ITS Surabaya, 21 Novemb. 2014, no. November 201, pp. 1-9, 2014. DOI: $10.1002 / \mathrm{rcm} .1134$

[16] Suryana, "Metodologi Penelitian: Metodologi Penelitian Model Prakatis Penelitian Kuantitatif dan Kualitatif," Univ. Pendidik. Indones., pp. 1-243, 2012. DOI: 10.1007/s13398 -014-0173-7.2.

[17] Creswell W. John, Research Design: Qualitative, Quantitave, and Mixed Methods Approaches, Third. United Kingdom, 2009.DOI: 10.2307/1523157.

[18] M. Mulyadi, "Penelitian Kuantitatif Dan Kualitatif Serta Pemikiran Dasar Menggabungkannya," J. Stud. Komun. dan Media, vol. 15, no. 1, p. 128, 2013.DOI: 10.31445/jskm.2011.150106.

[19] J. Sim, B. Saunders, J. Waterfield, and T. Kingstone, "Can sample size in qualitative research be determined a priori?," Int. J. Soc. Res. Methodol., vol. 21, no. 5, pp. 619-634, 2018. DOI: $10.1080 / 13645579.2018 .1454643$.

[20] M. Ziegler and D. Hagemann, "Testing the unidimensionality of items: Pitfalls and loopholes," Eur. J. Psychol. Assess., vol. 31, no. 4, pp. 231-237, 2015.DOI: 10.1027/1015-5759/a000309.

[21] I. Ben-gal, "Outlier detection Irad Ben-Gal Department of Industrial Engineering," Res. gate, no. November, pp. 0-11, 2014.DOI: 10.1007/0-387-25465-X.

[22] K. Laumann, T. Gärling, and K. M. Stormark, "Rating scale measures of restorative components of environments," $J$. Environ. Psychol., vol. 21, no. 1, pp. 31-44, 2001.DOI: 10.1006/jevp.2000.0179.

[23] N. Menold, "Rating-Scale Labeling in Online Surveys: An Experimental Comparison of Verbal and Numeric Rating Scales with Respect to Measurement Quality and Respondents' Cognitive Processes," Sociol. Methods Res., pp. 1-29, 2017. DOI: 10.1177/0049124117729694.

[24] M. E. Heilman, "Gender stereotypes and workplace bias," Res. Organ. Behav., vol. 32, pp. 113-135, 2012.DOI: 10.1016/j.riob.2012.11.003.

[25] J. C. Kaufman, "Self-reported differences in creativity by ethnicity and gender," Appl. Cogn. Psychol., vol. 20, no. 8, pp. 1065-1082, 2006.DOI: 10.1002/acp. 1255.

[26] J. Baer and J. C. Kaufman, "Gender differences in creativity," J. Creat. Behav., vol. 42, no. 2, pp. 75-105, 2008.DOI: 10.1002/j.2162-6057.2008.tb01289.x.

[27] J. De Rivera, "Assessing the basis for a culture of peace in contemporary societies," J. Peace Res., vol. 41, no. 5, pp. 531-548, 2004.DOI: 10.1177/0022343304045974.

[28] R. Sahara et al., "Student' s mathematical understanding ability based on self-efficacy Student' s mathematical understanding ability based on self- efficacy," J. Phys., pp. 1-8, 2017.DOI: 10.1088/1742-6596/909/1/012065.

[29] S. W. Chan, Z. Ismail, and B. Sumintono, "A Rasch Model Analysis on Secondary Students' Statistical Reasoning Ability in Descriptive Statistics," Procedia - Soc. Behav. Sci., vol. 129, pp. 133-139, 2014.DOI:10.1016/j.sbspro.20 14.03.658. 